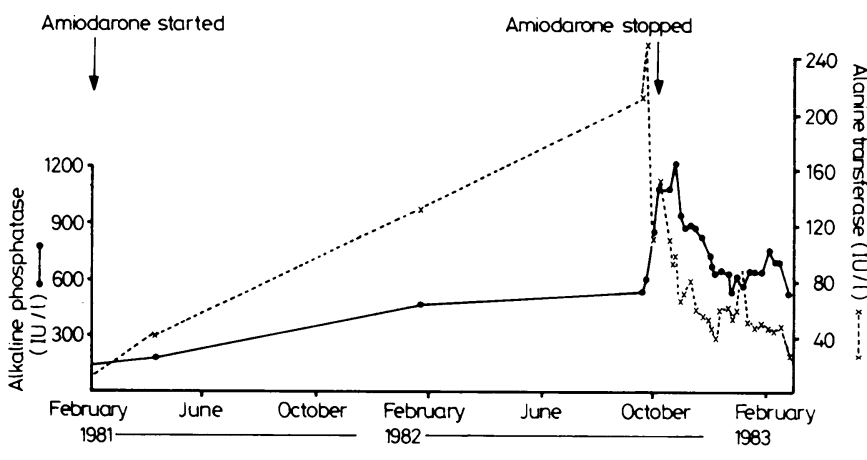

Serum enzyme concentrations in relation to amiodarone treatment.

Serial measurements of plasma amiodarone and desethyl amiodarone concentrations showed terminal elimination half lives of 51 and 53 days respectively. Postmortem amiodarone and desethyl amiodarone concentrations in liver were $170 \mathrm{mg} / \mathrm{kg}$ and $2960 \mathrm{mg} / \mathrm{kg}$ respectively, and the respective concentrations in muscle were 55 and $223 \mathrm{mg} / \mathrm{kg}$ one week after stopping amiodarone and 22 and 177 $\mathrm{mg} / \mathrm{kg}$ four months later.

\section{Discussion}

The fall in liver enzymes on stopping amiodarone suggests a causal relation between amiodarone ingestion and liver damage. The mechanism of toxicity is unknown but the accumulation of lamellated inclusion bodies suggests a drug induced disturbance of lipid metabolism and lysosomal function similar to that described in hepatitis and neuropathy related to perhexiline. ${ }^{3}$ Plasma concentrations of amiodarone and its main metabolite desethyl amiodarone were high on withdrawal of amiodarone, reflecting the large maintenance dose needed to control this patient's arrhythmia. The drug's large volume of distribution (in the order of 5000 litres) and long terminal elimination half life may explain the persistence of toxicity five months after withdrawal of amiodarone. The half life of amiodarone in our patient was similar to that reported in patients not developing liver disease 4 so a defect in amiodarone metabolism is unlikely to be the only cause of the toxicity.

Tricyclic antidepressants may also give rise to lamellated inclusion bodies in cultured cells, but not in human cells. ${ }^{5}$ The doxepin our patient was receiving could, however, have potentiated the adverse effects of amiodarone resulting in the rapid development of cirrhosis.

This case underlines the need to use the smallest effective dose of amiodarone in long term treatment. The drug and other potential hepatotoxins should be withdrawn if liver function test results become abnormal or neurological symptoms develop. Plasma measurements of amiodarone and desethyl amiodarone may be helpful.

We thank Drs P Hudgson, A R Morley, J Tregillus, and P J B Tilley for helpful advice, for the muscle and liver biopsy reports, and for carrying out the neurophysiological studies; and Miss Julie Elliott for typing the manuscript.

\section{References}

${ }^{1}$ McGovern B, Garan H, Kelly E, Ruskin JN. Adverse reactions during treatment with amiodarone hydrochloride. $B r$ Med $\mathcal{F} 1983 ; 287: 175-80$.

${ }^{2}$ Nademanee K, Singh BM. Adverse effects of amiodarone. $\mathcal{F} A M A 1982$; 248: 1448-9.

${ }^{3}$ Lemaire JF, Autret A, Biziere K, Romet-Lemone JL, Gray F. Amiodarone neuropathy: further arguments for human drug-induced neurolipidosis. Eur Neurol $1982 ; 21: 65-8$.

4 Holt DW, Tucker GT, Jackson P, Storey GCA. Amiodarone pharmacokinetics. Am Heart $\mathcal{F} 1983 ; \mathbf{1 0 6}: 840-7$.

${ }^{5}$ Lullmann-Rauch R. Drug-induced lysosomal storage disorders. Fron Biol $1979 ; 48: 49-130$.

(Accepted 29 March 1984)

\title{
Acute respiratory insufficiency after endoscopy for bleeding oesophageal varices
}

\author{
D C CRAWFORD, D W RYAN
}

\begin{abstract}
Two patients with alcoholic liver disease and gross ascites underwent endoscopic injection and compression by Sengstaken tube of oesophageal varices under general anaesthesia. Postoperatively both patients developed acute respiratory failure, which resolved after air had been aspirated from the stomach via the Sengstaken tube.

All air should be aspirated at the end of the procedure in patients with ascites who undergo endoscopy, and respiration should be carefully supervised postoperatively.
\end{abstract}

\footnotetext{
General Intensive Therapy Unit, Freeman Hospital, Newcastle upon Tyne NE7 7DN

D C CRAWFORD, MB, MRCP, registrar in anaesthetics

D W RYAN, MB, FFARCS, consultant clinical physiologist

Correspondence to: Dr D W Ryan.
}

\section{Introduction}

Diaphragmatic excursion is the principal muscular movement in achieving inspiration. ${ }^{1}$ In the presence of mechanical obstruction vital capacity and functional residual capacity fall appreciably. We report on two patients with alcoholic liver disease and gross ascites who developed acute respiratory failure after endoscopic injection of oesophageal varices under general anaesthesia.

\section{Case reports}

\section{CASE 1}

A 51 year old woman was admitted to this unit with bleeding oesophageal varices, gross ascites, and hepatic encephalopathy. Anaesthesia was induced with etomidate $12 \mathrm{mg}$ and suxamethonium $50 \mathrm{mg}$ and maintained with intermittent positive pressure ventilation together with $0.6 \%$ enflurane, oxygen, and $60 \%$ nitrous oxide. $\mathrm{Her}$ varices were injected with $5 \%$ ethanolamine oleate endoscopically and then compressed by a Sengstaken tube. 
Postoperatively, she rapidly recovered spontaneous respiration. Within minutes after extubation she developed acute respiratory failure followed by cardiovascular collapse. There was no evidence of further bleeding. She was rapidly reintubated and resuscitated, and on her return to the unit her girth had increased to $1.4 \mathrm{~m}$ and her abdomen was tympanic on percussion. Air was aspirated by suction on the Sengstaken tube and her cardiovascular system restabilised. She was extubated and returned to the ward.

\section{CASE 2}

A 40 year old man with alcoholic liver disease was admitted after a massive haematemesis. Anaesthesia was induced with etomidate $10 \mathrm{mg}$ and suxamethonium $100 \mathrm{mg}$ and maintained with alcuronium $15 \mathrm{mg}, 0.6 \%$ enflurane, oxygen, and $60 \%$ nitrous oxide and intermittent positive pressure ventilation. At emergency endoscopy his varices were injected and a Sengstaken tube left in place.

Postoperatively, residual neuromuscular blockade was antagonised by atropine $1.2 \mathrm{mg}$ and neostigmine $2.5 \mathrm{mg}$ and spontaneous respiration returned. He was extubated in the left lateral position but, when turned on to his back, became apnoeic with circulatory collapse. $\mathrm{He}$ was again turned to the left lateral position, reintubated, and ventilated. Air was aspirated from the stomach via the Sengstaken tube and intermittent positive pressure ventilation was continued for two days before he could maintain adequate spontaneous respiration.

\section{Discussion}

Many abdominal conditions restrict diaphragmatic movement. These include simple obesity, pregnancy, ovarian cysts, and peritoneal dialysis, as well as ascites and gastric distension. Our two patients were already severely compromised by their ascites and the reduction in functional residual capacity that occurred in the supine position and after anaesthesia. Air insufflated by the endoscopist during variceal injection was retained in the stomach, which was already distended with the gastric balloon of the Sengstaken tube containing $400 \mathrm{ml}$ air. This may have tipped these patients into acute respiratory failure. The clinical improvement after gastric decompression would tend to support this hypothesis. A pilot study investigating respiratory function in the presence of gross ascites has shown a reduction in vital capacity by up to $50 \%$ of predicted values, and we propose to study this further.

High intra-abdominal pressures are known to reduce venous return and impair myocardial performance. ${ }^{2}$ The cardiovascular collapse seen in these two patients may have been due partly to compression of the inferior vena cava, the so called "supine hypotension syndrome" of pregnancy. Certainly the second patient (case 2) showed some clinical improvement when he was turned to the left lateral position before resuscitation.

Patients with ascites who undergo endoscopy should have all air aspirated at the end of the procedure, and careful respiratory supervision should be continued in an intensive care unit during the early postoperative phase.

\section{References}

1 Nunn JF. Applied respiratory physiology. Sevenoaks: Butterworth, 1977. ${ }^{2}$ Guazi M, Polese A, Magrini F, Fiorentini C, Olivari M. Negative influence of ascites on the cardiac function of cirrhotic patients. $\mathrm{AmF} \mathrm{Med}$ $1975 ; 59: 165-70$.

(Accepted 23 February 1984)

\begin{abstract}
A case of pseudoporphyria associated with excessive consumption of brewers' yeast was studied. Detailed analysis of the yeast tablets by high performance liquid chromatography showed the presence of dicarboxylic deuteroporphyrin, mesoporphyrin, and protoporphyrin; coproporphyrin I and III isomers; and uroporphyrin I and III isomers. The faecal porphyrin concentration of the patient taking yeast tablets was significantly increased, resembling the excretion pattern in variegate porphyria.

Any patient showing an unusual porphyrin excretion pattern on high performance liquid chromatography should be investigated for a possible dietary cause.

\footnotetext{
Division of Clinical Cell Biology, MRC Clinical Research Centre, Harrow, Middlesex HA1 3UJ

C K LIM, PHD, scientific officer

J M RIDEOUT, FIMLS, chief research officer

T J PETERS, PHD, FRCP, professor and head of division
}

\section{Introduction}

Brewers' yeast is sold as vitamin enriched tablets with added thiamine, riboflavine, and nicotinic acid. Although certain strains of yeast are known to accumulate porphyrins, ${ }^{1}{ }^{2}$ there have been no reports of porphyrins in commonly taken vitamin enriched yeast tablets. Diagnosis of the porphyrias requires the routine identification and determination of porphyrins in blood, urine, and faeces. In recent years this has been carried out increasingly by high performance liquid chromatography. ${ }^{3-6}$

We report a case of pseudoporphyria associated with consumption of brewers' yeast and describe the detailed analysis of porphyrins in these tablets and their relation to the biochemical identification of the porphyrias.

\section{Present study}

CASE REPORT

A 24 year old man suffered persistently from episodic abdominal pain. Since no other abnormalities were found, screening tests for porphyrias were performed. He had normal urinary concentrations of 5-aminolaevulinate $(15 \mu \mathrm{mol} / \mathrm{l}(201 \mu \mathrm{g} / 100 \mathrm{ml})$; normal range $0-40 \mu \mathrm{mol} / 1(0-536 \mu \mathrm{g} / 100 \mathrm{ml}))$, porphobilinogen $(1.6 \mu \mathrm{mol} / 1(36 \mu \mathrm{g}$ $100 \mathrm{ml})$; normal range $0-8 \mu \mathrm{mol} / \mathrm{l}(0-181 \mu \mathrm{g} / 100 \mathrm{ml}))$, and total 